\title{
Photoluminescence and intrinsic ferromagnetism of Fe doped zinc oxide
}

\author{
Bidyarani Maibam $^{1} \cdot$ Saptaka Baruah $^{1} \cdot$ Sanjeev Kumar $^{1}$ (]
}

Received: 6 April 2020 / Accepted: 16 September 2020 / Published online: 21 September 2020

(c) Springer Nature Switzerland AG 2020

\begin{abstract}
$\mathrm{Zn}_{1-x} \mathrm{Fe}_{x} \mathrm{O}$ nanoparticles with different doping concentration i.e. $(x=0,0.01,0.02,0.03,0.04,0.05)$ were successfully synthesized via hydrothermal method. The crystal structure, morphology, optical and magnetic properties were studied by $\mathrm{X}$-ray diffraction, field emission scanning electron microscope, UV-visible, photoluminescence spectra (PL) and vibrating sample magnetometer. The experimental results show that all the samples possess a single phase hexagonal wurtzite structure, no impurity phase was observed. The crystallite size decreases with the increase in Fe concentration. Optical absorption analysis by UV-visible exhibits a slight blueshift in the bandgap with increasing doping concentration. PL spectra shows that the emission peak in the UV region is absent for all the samples. All the emission peaks are in the visible region. Shifting of PL emission peaks is not observed indicating that the intrinsic defects are consistent. The magnetic observation indicated that all the samples including pure zinc oxide exhibit room temperature ferromagnetism (RTFM). The observed RTFM is attributed to the bound magnetic polaron that arises due to the presence of singly ionized oxygen vacancy $\left(V_{\mathrm{o}}\right)$ as indicated by PL spectra.
\end{abstract}

Keywords $\mathrm{ZnO} \cdot$ Hydrothermal $\cdot$ Fe-doped $\cdot$ Photoluminescence $\cdot$ Magnetic properties

\section{Introduction}

Diluted magnetic semiconductors (DMSs) are the materials formed by replacing cations of nonmagnetic semiconductors by magnetic ions such as transition metals (TM) ions or rare earth ions [1]. Ferromagnetism observed in DMS has led to its intense research because of their potential applications in spintronic devices, which uses both the spin in magnetic materials and charge of electrons [2]. Moreover, doping of transition metal into wide band gap semiconductor also leads to the tuning of optical and ferromagnetic properties [3]. Intrinsic ferromagnetism with high Curie temperature (above room temperature) is the principal requirement of DMSs for the application in spintronic devices [4]. Thus, efforts are made to produce TM metal doped wide bandgap semiconductor exhibiting room temperature ferromagnetism (RTFM). Zinc oxide $(\mathrm{ZnO})$ is II-VI wide band gap $\left(E_{\mathrm{g}} \sim 3.37 \mathrm{eV}\right)$ and large exciton binding energy ( $60 \mathrm{meV}$ ) compound semiconductor with hexagonal wurtzite structure of $P 6_{3} \mathrm{mc}$ space group [5]. Requirement of Curie temperature above room temperature (RT) and intrinsic ferromagnetism (FM), rather than the ferromagnetism because of magnetic clusters or secondary phases of dopants for spintronics application makes transition metal doped $\mathrm{ZnO}$ a favorable system owing to observation of RTFM in several $\mathrm{ZnO}$ based system including $\mathrm{Mn}$-, Fe- and Co-doped $\mathrm{ZnO}$ [6]. Results quite contradictory to each other are reported for ferromagnetism in transition metal doped $\mathrm{ZnO}$. Liu et al. [7] reported RTFM and explains it as the intrinsic property of Fe doped $\mathrm{ZnO}$. Reports suggesting that transition metal does not play any role in the magnetism of $\mathrm{Mn}$ and $\mathrm{Fe}$

Sanjeev Kumar, sanjeev.kumar@rgu.ac.in | 'Department of Physics, Center of Advance Research, Rajiv Gandhi University, Rono Hills, Itanagar, Arunachal Pradesh, India. 
doped $\mathrm{ZnO}$ thin films are also available [8]. Bhargava et al. [9] observed ferromagnetism in $\mathrm{Cr}$ doped $\mathrm{ZnO}$. Taher et al. [10] observed ferromagnetism in nanostructure Codoped $\mathrm{ZnO}$ thin films reasonably caused by the oxygen vacancies introduced in the films during the hydrothermal growth. RTFM was also reported by Mishra et al. in Fe doped $\mathrm{ZnO}$ nanostructures synthesized using chemical root and attributed its cause to Zinc vacancy $\left(Z n_{i}\right)$ while Wei et al. also observed ferromagnetism in Fe doped $\mathrm{ZnO}$ and attributed it to secondary phase for high doping concentration [11, 12]. Even though large numbers of reports are available in literature, there is a conflict for the origin of observed room temperature ferromagnetism in the transition metal doped ZnO DMS.

In the present work, our aim is to provide a better understanding of the origin of room temperature ferromagnetism. For this purpose, diluted magnetic semiconductor $\mathrm{Zn}_{1-x} \mathrm{Fe}_{x} \mathrm{O}$ with different doping concentration $(x=0,0.01,0.02,0.03,0.04,0.05)$ is synthesized via hydrothermal method. The magnetic property is studied by using vibrating sample magnetometer (VSM). The structure and surface morphology is investigated by X-ray diffraction (XRD) and field emission scanning electron microscope (FESEM). The optical properties are studied with the help of UV-visible and photoluminescence (PL) spectra.

\section{Experimental details}

$\mathrm{Zn}_{1-x} \mathrm{Fe}_{x} \mathrm{O}(x=0,0.01,0.02,0.03,0.04,0.05)$ nanoparticles are prepared by hydrothermal method. An aqueous solution of $1 \mathrm{M}$ zinc nitrate hexahydrate $5 \mathrm{M}$ sodium hydroxide and $1 \mathrm{M}$ ferric nitrate nonahydrate solutions are prepared in double distilled water. Zinc nitrate hexahydrate and ferric nitrate nonahydrate solutions are mixed according to the required amounts and stirred at room temperature. Sodium hydroxide solution is added dropwise to it. After being stirred for $2 \mathrm{~h}$, the mixture is transferred into a $200 \mathrm{ml}$ Teflon lined stainless steel autoclave and is kept in an oven at $100^{\circ} \mathrm{C}$ for $6 \mathrm{~h}$. It is then allowed to cool down naturally at room temperature. The obtained product is washed with distilled water and dried at $100^{\circ} \mathrm{C}$ for $24 \mathrm{~h}$. The samples are then heated at $500{ }^{\circ} \mathrm{C}$ for $2 \mathrm{~h}$. Figure 1 shows the flowchart depicting hydrothermal method used for the synthesis of $\mathrm{Zn}_{1-x} \mathrm{Fe}_{x} \mathrm{O}(x=0,0.01,0.02,0.03,0.04$, 0.05).

The structural and morphological characterizations of the samples are performed using X-ray diffractometer (Model: Smartlab XRD) and field emission scanning electron microscope (FESEM, Model: Carl Zeiss Ultra Plus). The optical properties are studied by using UV-visible spectrophotometer (Model: Cary 60 UV-Vis) and photoluminescence spectrophotometer (Model: Cary Eclipse

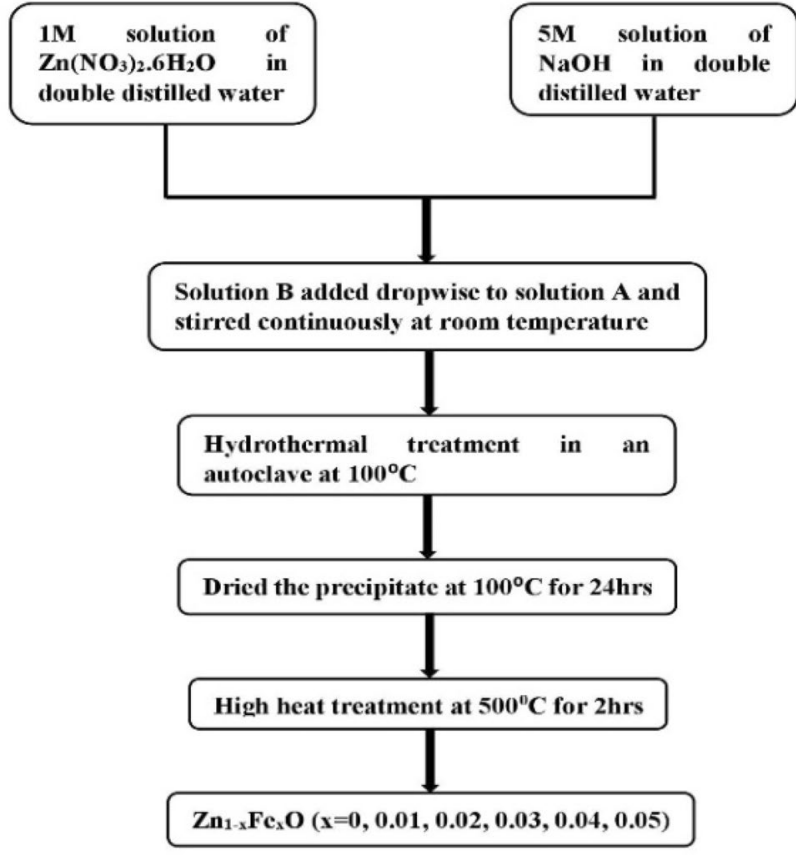

Fig. 1 Flowchart depicting hydrothermal method used for the synthesis of $\mathrm{Zn}_{1-x} \mathrm{Fe}_{x} \mathrm{O}$

Fluorescence Spectrophotometer). Vibrating sample magnetometer (VSM, Model: Quantum Design VERSALAB) was used for magnetic characterization.

\section{Structural analysis}

\subsection{X-ray diffraction}

Figure 2a shows the XRD pattern of $\mathrm{Zn}_{1-x} \mathrm{Fe}_{x} \mathrm{O}$ nanoparticles. The diffraction peaks in the XRD pattern corresponds to the diffraction of (100), (002), (101), (102), (110) planes indicating the formation of hexagonal wurtzite structure of $\mathrm{ZnO}$ with a space group $P 6_{3} m c$. Furthermore, no traces of impurity or secondary phases within the detection limit of XRD and no obvious diffraction patterns of Iron (Fe) species such as $\mathrm{Fe}, \mathrm{Fe}_{2} \mathrm{O}_{3}$, and $\mathrm{Fe}_{3} \mathrm{O}_{4}$ are found in the samples of $1-5 \%$ Fe doped $\mathrm{ZnO}$. The result indicates the successful incorporation of all Fe ions in the host $\mathrm{ZnO}$ crystal lattice. It is seen from the XRD pattern that with an increase Fe concentration the peak shifts towards the lower angle as compared to the pristine $\mathrm{ZnO}$ up to 3\% doping and then again shift towards the higher angle being nearly equal to that for pristine $\mathrm{ZnO}$ at $4 \%$. These results may be ascribed to the valence state of $\mathrm{Fe}$ ions. Fe ions are capable of existing as $\mathrm{Fe}^{2+}, \mathrm{Fe}^{3+}$ stably in compounds. In this paper, dopant ions are introduced into the host $\mathrm{ZnO}$ through ferric nitrate, so Fe would be in $\mathrm{Fe}^{3+}$ valence state. It is known that zinc act 

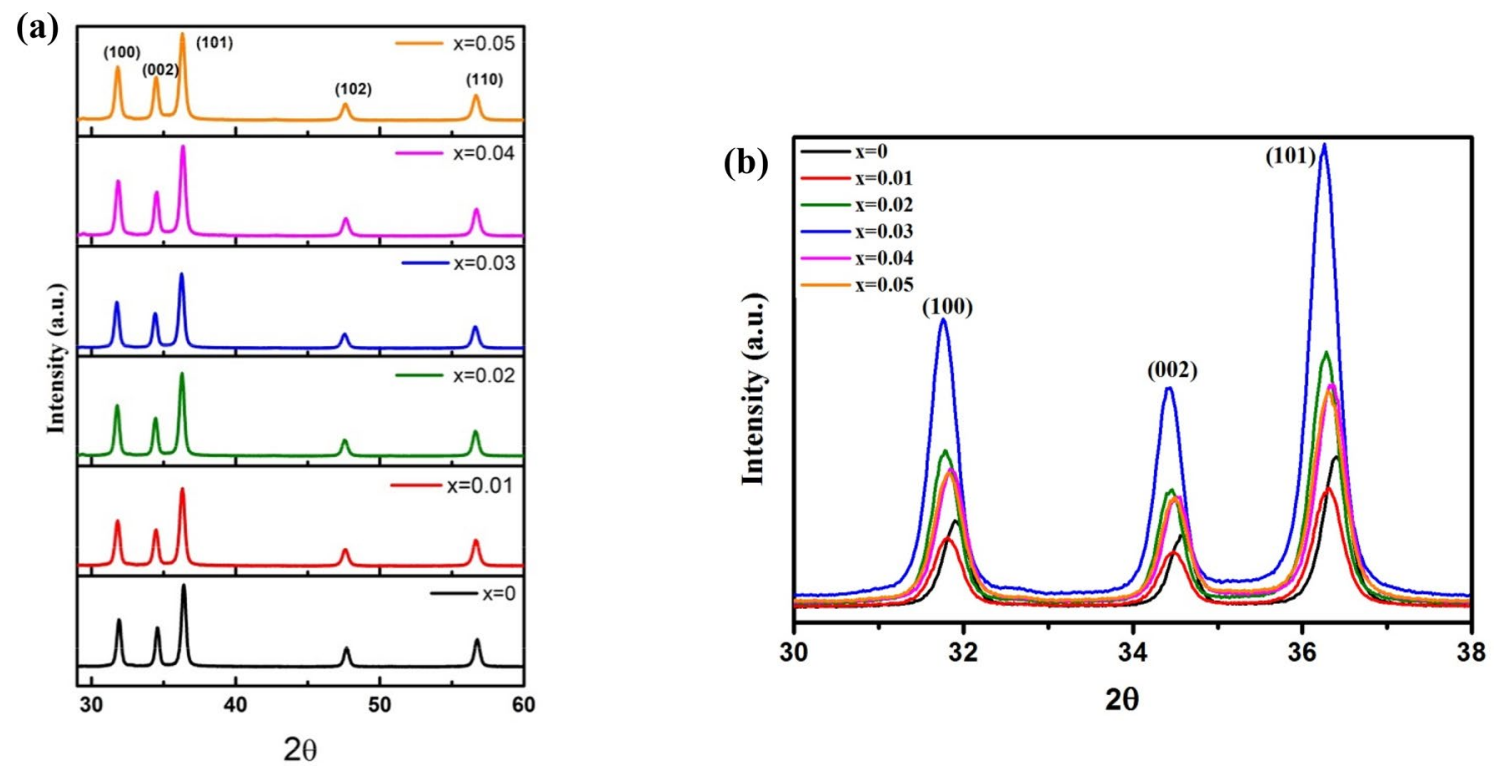

Fig. 2 a XRD pattern of $\mathrm{Zn}_{1-x} \mathrm{Fe}_{x} \mathrm{O}(x=0,0.01,0.02,0.03,0.04,0.05)$. b XRD pattern of first three peaks of $\mathrm{Zn}_{1-x} \mathrm{Fe}_{x} \mathrm{O}(\mathrm{x}=0,0.01,0.02,0.03$, $0.04,0.05$ )

as a reducing agent in changing $\mathrm{Fe}^{3+}-\mathrm{Fe}^{2+}[24]$. So, transition of $\mathrm{Fe}^{3+}-\mathrm{Fe}^{2+}$ is much expected as the host being $\mathrm{ZnO}$ in this case. The existence of $\mathrm{Fe}$ in $\mathrm{Fe}^{2+}$ is reported where the diffraction angle decreases with Fe concentration while the existence of iron as $\mathrm{Fe}^{3+}$ is reported where the diffraction angle increases [13-15]. Taking the peak position into consideration and from the existing reports, it can be inferred that $\mathrm{Fe}^{2+}$ and $\mathrm{Fe}^{3+}$ coexist in the Fe doped $\mathrm{ZnO}$ samples [16]. The shifting of peaks may also be due to the strain developed in the lattice due to doping. Broadening of peak, apart from its shift can be explained based on grain size reduction with $\mathrm{Fe}$ atom incorporation in $\mathrm{ZnO}$. The ionic radii of $\mathrm{Fe}^{2+}, \mathrm{Fe}^{3+}$ and $\mathrm{Zn}^{2+}$ are $0.078,0.068$ and $0.074 \mathrm{~nm}$ respectively [17]. Substitution of $\mathrm{Zn}^{2+}$ with $\mathrm{Fe}^{2+}$, $\mathrm{Fe}^{3+}$ in the lattice site may cause lattice distortion resulting in strain in $\mathrm{ZnO}$ because of the difference in ionic radii of $\mathrm{Fe}^{2+}$ and $\mathrm{Fe}^{3+}$ with $\mathrm{Zn}^{2+}$ [18]. Fe ions need to have a balanced state of $2+$ for maintaining the charge neutrality to properly substitute $\mathrm{Zn}^{2+}$ ionic sites. So, the balance state $\mathrm{Fe}^{3+}$ is likely to distort the lattice structure for maintaining the charge neutrality [19].

Figure $2 \mathrm{~b}$ shows a large difference in intensity of XRD peaks for $1 \%$ and $3 \%$ Fe doped $\mathrm{ZnO}$. The difference in intensity is due to the difference in their crystalline quality $[13,20]$. The full width half maximum (FWHM) increases for $1 \%$ Fe doped $\mathrm{ZnO}$ indicating the decrease in the crystalline quality compares to pristine $\mathrm{ZnO}$. The decrease in crystalline quality may be because of the lattice disorder and strain experience due to the incorporation of Fe ions in $\mathrm{ZnO}$ matrix [21]. But as the doping of Fe increases to $2 \%$, FWHM value decreases suggesting an increase in crystalline quality. The crystalline quality then again keeps on declining with the increase in doping up to $5 \%$ as implied by the increase in FWHM value. The increase in the crystallinity of the $2 \%$ Fe doped $\mathrm{ZnO}$ in our experiment may be ascribed to the formation of favorable nucleation centers from the dopant atoms for $\mathrm{ZnO}$ crystal growth. The decline in crystalline quality in $5 \%$ doping may be because of the saturation of newer nucleation centers or because of the ionic radii difference of $\mathrm{Zn}^{2+}$ and Fe ions [18]. Substitution of a large number of Fe ions in $\mathrm{Zn}^{2+}$ lattice sites leads to an increase in lattice distortion causing a lager strain which affects the crystal growth of $\mathrm{ZnO}$.

The (101) preferred orientation with maximum intensity has been observed in the XRD pattern. The average crystallite size (D) of the samples is estimated from XRD line width of (101) peak by using Scherrer's equation [22]. The crystalline size value of pristine and Fe doped $\mathrm{ZnO}$ is shown in Fig. 3. The crystallite size is in accordance with the FWHM values. The calculated values of $a, c, c / a, D, d$, volume, bond length, internal parameter $(u)$ and distortion degree $(R)$ are given in Table 1 [22].

The $c / a$ ratio of pristine $\mathrm{ZnO}$ as well as Fe doped samples is less than the $c / a$ ratio of ideal stoichiometry wurtzite structure ratio i.e. 1.633 indicating the presence of oxygen vacancies and zinc vacancies [23]. The calculated values of bond length vary from 1.9692 to 1.9735 . Variation of bond length is not monotonous with doping concentration. The non-monotonous variation of bond length may be because of the strain present in the samples and a slight change in $R$ is also observed [24]. 


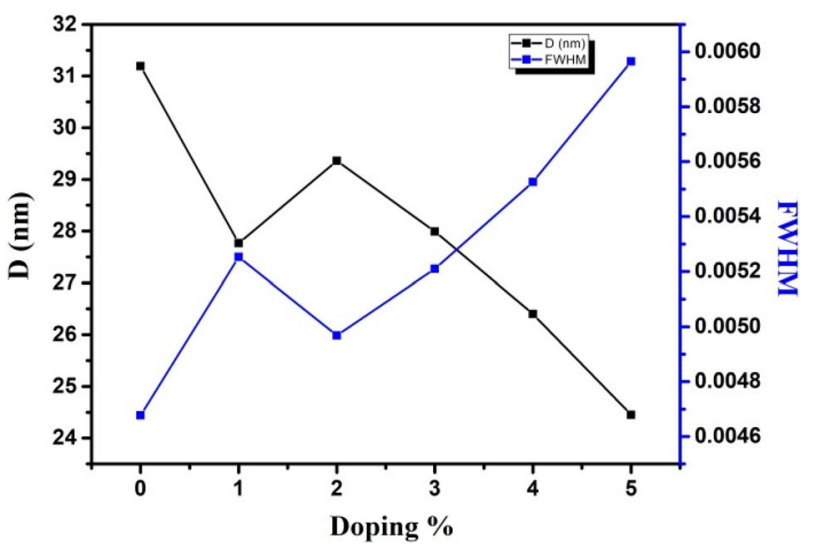

Fig. 3 Average crystallite size and FWHM of $\mathrm{Zn}_{1-x} \mathrm{Fe}_{x} \mathrm{O}(\mathrm{x}=0,0.01$, $0.02,0.03,0.04,0.05$ )

\subsection{SEM analysis}

The morphology of the synthesized $\mathrm{Zn}_{1-x} \mathrm{Fe}_{x} \mathrm{O}(x=0,0.03$, 0.05 ) materials are studied by field emission scanning electron microscope (FESEM). The FESEM images imply the change of shape and morphology of $\mathrm{ZnO}$ nanoparticles with doping. Figure 4a shows formation of a mixture of rod like and nanoflakes like morphology in pristine $\mathrm{ZnO}$. In contrast, the $\mathrm{Zn}_{0.97} \mathrm{Fe}_{0.03} \mathrm{O}$ and $\mathrm{Zn}_{0.95} \mathrm{Fe}_{0.05} \mathrm{O}$ doped $\mathrm{ZnO}$ in Fig. $4 \mathrm{~b}$, c respectively showed cone-like particles that are formed may be due to the asymmetrical and multidimensional growth of $\mathrm{ZnO}$ particles [25]. It is difficult to say something about the average grain size of the pristine and doped samples as the particles seems to be agglomerated for these images.

Energy dispersive $\mathrm{X}$-ray analysis (EDAX) study is carried out for observing the elemental composition of synthesized samples and to verify the successful incorporation of dopants and the formation of $\mathrm{ZnO}$ nanoparticles. EDAX signals of pristine $\mathrm{ZnO}$ and $\mathrm{Zn}_{0.95} \mathrm{Fe}_{0.05} \mathrm{O}$ are shown in Fig. 5. For pristine $\mathrm{ZnO}$ nanoparticles, sharp signals of $\mathrm{Zn}$ and oxygen were found confirming the formation of $\mathrm{ZnO}$ nanoparticles. For Fe doped sample, Fe signals in addition to $\mathrm{Zn}$ and oxygen were also found, confirming the successfully incorporated of Fe in the $\mathrm{ZnO}$.

\section{Optical properties}

\subsection{UV-visible analysis}

We explore and analyze pristine and Fe doped ZnO nanoparticles energy bandgap using UV-visible spectroscopy. The optical bandgap of the pristine and Fe doped sample is calculated by using the Tauc relation. Figure 6a shows the Tauc plot and the variation of bandgap with doping concentration is shown in Fig. 6b. Values of the bandgap are also tabulated in Table 2.

Table 1 Structural parameters of $\mathrm{Zn}_{1-x} \mathrm{Fe}_{x} \mathrm{O}(x=0,0.01,0.02,0.03,0.04,0.05)$

\begin{tabular}{llllllllll}
\hline $\mathrm{Zn}_{1-x} \mathrm{Fe}_{x} \mathrm{O}$ & $a=b(\AA)$ & $c(\AA)$ & $c / a$ & $D(\mathrm{~nm})(101)$ & $d(\AA)(101)$ & Volume $(\AA))^{3}$ & Bond length $(\AA)$ & $u$ & $R$ \\
\hline$x=0$ & 3.2355 & 5.1845 & 1.6024 & 31.1940 & 2.4653 & 47.0007 & 1.9692 & 0.379826 & 1.019122 \\
$x=0.01$ & 3.2434 & 5.1961 & 1.6020 & 27.7665 & 2.47186 & 47.3385 & 1.9739 & 0.379879 & 1.019327 \\
$x=0.02$ & 3.2474 & 5.1990 & 1.6009 & 29.3585 & 2.47318 & 47.4810 & 1.9759 & 0.38005 & 1.02 \\
$x=0.03$ & 3.2494 & 5.2020 & 1.6009 & 27.9918 & 2.4745 & 47.5655 & 1.97708 & 0.380064 & 1.020055 \\
$x=0.04$ & 3.2415 & 5.1845 & 1.5994 & 26.4017 & 2.46792 & 47.1743 & 1.9717 & 0.380303 & 1.020993 \\
$x=0.05$ & 3.2435 & 5.1932 & 1.6011 & 24.4524 & 2.47186 & 47.3119 & 1.9735 & 0.380025 & 1.019901 \\
\hline
\end{tabular}

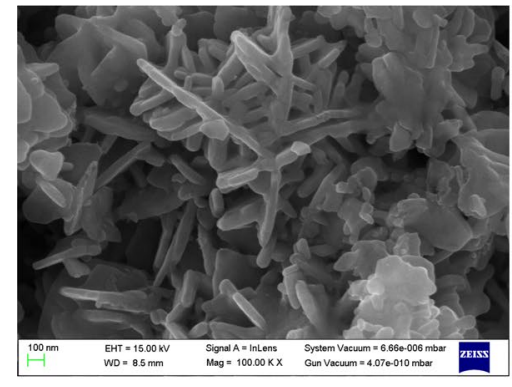

(a)

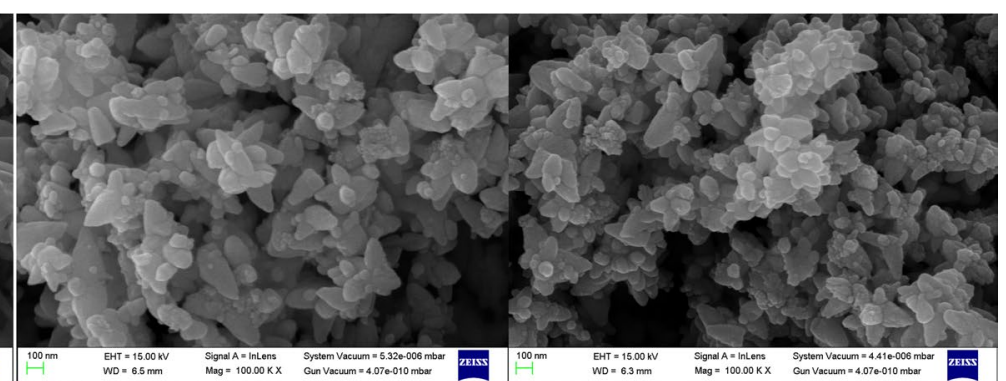

(b)

Fig. 4 SEM micrographs of $\mathrm{Zn}_{1-x} \mathrm{Fe}_{x} \mathrm{O} . \mathbf{a} x=0, \mathbf{b} x=0.03$ and $\mathbf{c} x=0.05$ 


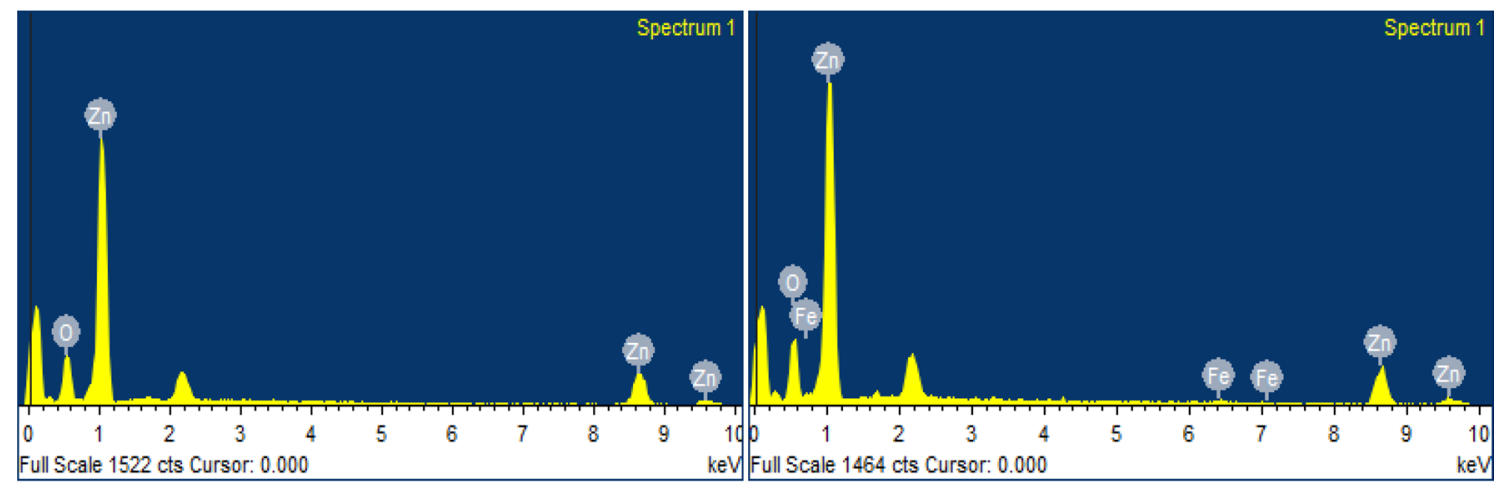

(a)

(b)

Fig. 5 EDAX pattern of $\mathrm{Zn}_{1-x} \mathrm{Fe}_{x} \mathrm{O} . \mathbf{a} x=0$ and $\mathbf{b} x=0.05$
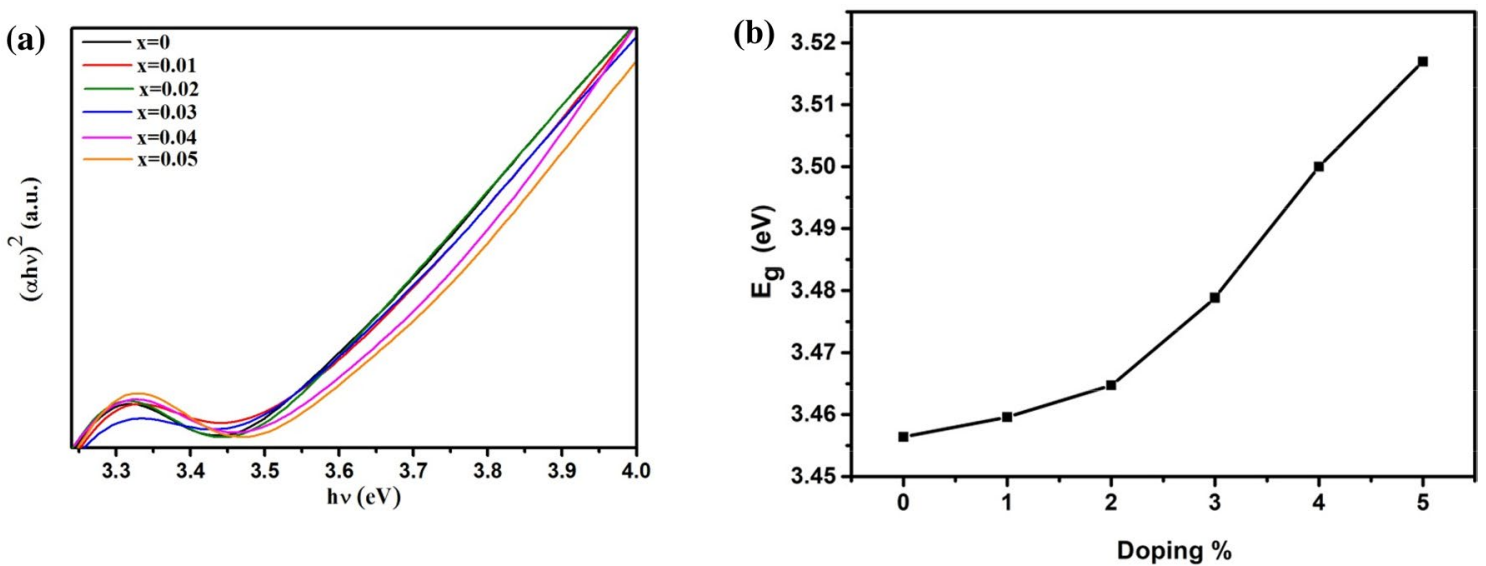

Fig. 6 a Band gap calculation of $\mathrm{Zn}_{1-x} \mathrm{Fe}_{x} \mathrm{O}(\mathrm{x}=0,0.01,0.02,0.03,0.04,0.05)$ nanoparticles and $\mathbf{b}$ doping percentage versus $E_{\mathrm{g}}$

Table 2 Summary of bandgap $\left(E_{\mathrm{g}}\right)$ of $\mathrm{Zn}_{1-x} \mathrm{Fe}_{x} \mathrm{O}(x=0,0.01$, $0.02,0.03,0.04,0.05$ )

\begin{tabular}{ll}
\hline $\mathrm{Zn}_{1-x} \mathrm{Fe}_{x} \mathrm{O}$ & $E_{\mathrm{g}}(\mathrm{eV})$ \\
\hline$x=0$ & 3.456 \\
$x=0.01$ & 3.459 \\
$x=0.02$ & 3.464 \\
$x=0.03$ & 3.478 \\
$x=0.04$ & 3.5 \\
$x=0.05$ & 3.516
\end{tabular}

The exciton Bohr radius of $\mathrm{ZnO}$ is much larger than the obtained average crystallite size. Therefore, the quantum confinement effect is not the major reason for the change in the bandgap of prepared samples [26]. The increase in bandgap may be due to the strain experienced by the doped sample. The result obtained is in agreement with the result reported by Parra-Palomino et al. [27] where they observed a large blueshift in bandgap as the concentration of the dopant increase. The obtained bandgap is also in accordance with the result obtained by Hammad et al. [15] who explain the blue shift behavior based on Moss-Burstein theory. According to this theory, $\mathrm{ZnO}$ nanoparticle is $n$-type semiconductor and due to doping the Fermi level shifts inside the conduction band. The absorption edge shifts to higher energy as the states below such shifting in the conduction band are filled leading to the widening of bandgap. The shifting of Fermi level towards the conduction band may be attributed to the additional carriers or $d-d$ transition from Fe. Rekha et al. and Arun et al. also explain the blue shift behavior of their sample based on the Moss-Burstein theory $[28,29]$. The increase in bandgap or the blue shift behavior for the Fe doped sample with respect to that of pristine $\mathrm{ZnO}$ may also be because of the $s p$ - $d$ exchange interaction of localized $d$ electron and band electrons as explained by Pal Singh et al. [30]. 


\subsection{Photoluminescence (PL) characteristic}

The PL properties of pristine and Fe-doped $\mathrm{ZnO}$ nanoparticles are also studied. The photoluminescence is recorded at room temperature with an excitation wavelength of $330 \mathrm{~nm}$. Figure 7 shows the PL spectra at RT for all the samples. The inset of Fig. 7 represents the PL spectra of pristine $\mathrm{ZnO}$ deconvoluted into six peaks. Even though PL spectra of $\mathrm{ZnO}$ have been studied extensively, the source of visible range emission bands remains controversial. The typical photoluminescence spectra of $\mathrm{ZnO}$ have emission bands in the UV and visible regions. Usually, the UV luminescence peak is considered as the characteristics emission of $\mathrm{ZnO}$ and it is ascribed to the band edge emission or transition of exciton [31]. It is exciting to note that there is no UV emission peak in the PL spectra of prepared samples. This signifies that the recombination of exciton pairs of the prepared samples occurs at the non-radiative centers [32]. The disappearance of UV emission peak may also be attributed to a much higher intensity of visible emission due to an increase in defect density or it may also be because its excitation energy is significantly lower than its bandgap energy [33].

PL spectra confirmed that all the samples exhibited six peaks in the visible region. The peak near $416 \mathrm{~nm}(2.98 \mathrm{eV})$ in the PL spectra arises due to violet emission. This may arise because of the transition from conduction band (CB) to deep holes trapped levels above the valence band (VB) [34]. A single distinct peak centered about $458 \mathrm{~nm}$ $(2.70 \mathrm{eV})$ in the blue band $(2.75-2.63 \mathrm{eV})$ may be attributed to the direct recombination of a conduction electron in the CB and a hole in the VB [35]. The blue green emission peak centered about $486 \mathrm{~nm}(2.55 \mathrm{eV})$ may occur

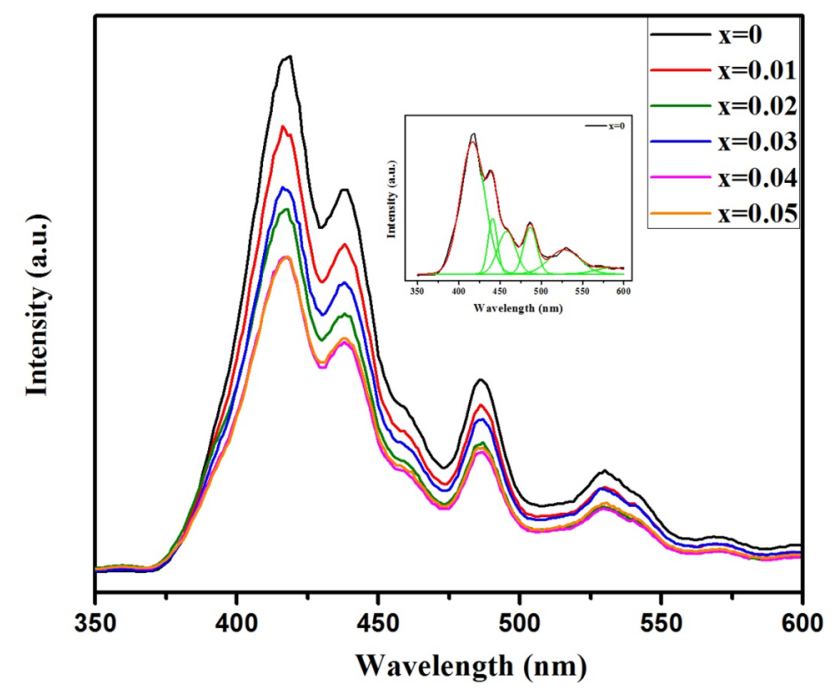

Fig. 7 PL spectra of $\mathrm{Zn}_{1-x} \mathrm{Fe}_{x} \mathrm{O}(\mathrm{x}=0,0.01,0.02,0.03,0.04,0.05)$ and the inset represents the deconvoluted spectra of pure $\mathrm{ZnO}$ because of the electronic transition of donor level $Z n_{i}$ to acceptor level Zinc vacancy $\left(V_{Z n}\right)$ [36]. Green emission peak centered about $528 \mathrm{~nm}(2.35 \mathrm{eV})$ is credited to defects related to oxygen vacancies because of the recombination of photogenerated holes and electron trapped by singly ionized oxygen vacancies $\left(V_{0}\right)$ [37]. $V_{0}$ are known as color centers (or $F$ centers) and are also an important set of point defects in oxides. In the $\mathrm{ZnO}$ lattice, it shows three dissimilar charged states as $\mathrm{F}^{++}, \mathrm{F}^{+}, \mathrm{F}^{0}$. The $\mathrm{F}^{+}$oxygen vacancy which is singly occupied can contribute in activating bound magnetic polarons (BMP) and magnetic moment in DMSs. However, $\mathrm{F}^{++}$and $\mathrm{F}^{0}$ vacancies do not induce $\mathrm{FM}$ in $\mathrm{ZnO}$ since they have spin zero ground states [14]. The broad peak centered about $584 \mathrm{~nm}(2.12 \mathrm{eV})$ in the range $550-600 \mathrm{~nm}(2.25-2.06 \mathrm{eV})$ is dedicated to the defect related transition originating from excess oxygen. Non-shifting of luminescence peaks in the visible range indicates that the intrinsic defects are consistent in all the samples [24]. Quenching of the luminescence peaks may be because of non-radiative recombination or may be due to the preferential occupation of $\mathrm{Fe}^{3+}$ ions by photogenerated electrons inducing trap centers [38].

\section{Magnetic properties}

To study the effect of Fe doping on the magnetic behavior of $\mathrm{ZnO}$, the magnetization versus applied magnetic field curve obtain from VSM data performed at RT is studied. Figure 8 shows the $\mathrm{M}-\mathrm{H}$ curves of $\mathrm{Zn}_{1-x} \mathrm{Fe}_{x} \mathrm{O}(x=0,0.01$, $0.02,0.03,0.04,0.05)$ nanoparticles. It is observed that the $\mathrm{M}-\mathrm{H}$ curves of the pristine and doped samples do not saturate even at high applied fields. The $\mathrm{M}-\mathrm{H}$ curve for all the samples comprises a linear part possibly because of the small paramagnetic (PM) and superparamagnetic (SPM) contribution in addition to a distinct ferromagnetic ordering confirmed by hysteresis behavior of the curve at lower field region [39]. Pristine $\mathrm{ZnO}$ ferromagnetism termed as $d^{0}$ ferromagnetism may arise because of the presence of $V_{\mathrm{o}}$ defects and is supported by the PL spectra [40]. There are also reports indicating the role of $Z n_{i}$ and $V_{0}$ in maintaining pure $\mathrm{ZnO}$ magnetic behavior. RTFM may be due to extrinsic phenomena such as the formation of cluster or secondary phase of dopant ions and intrinsic phenomena such as exchange interaction [30]. The XRD pattern indicates that there is no formation of secondary phases such as $\mathrm{Fe}_{2} \mathrm{O}_{3}, \mathrm{Fe}_{3} \mathrm{O}_{4}$, etc. Therefore, the observed ferromagnetism in our sample cannot be attributed to the formation of the secondary phase or cluster due to the doping of Fe. So, it may be because of the intrinsic phenomena and not due to the extrinsic phenomena. Number of models and concepts has been proposed to explain the room temperature ferromagnetism such as (a) hole mediated 
(a)

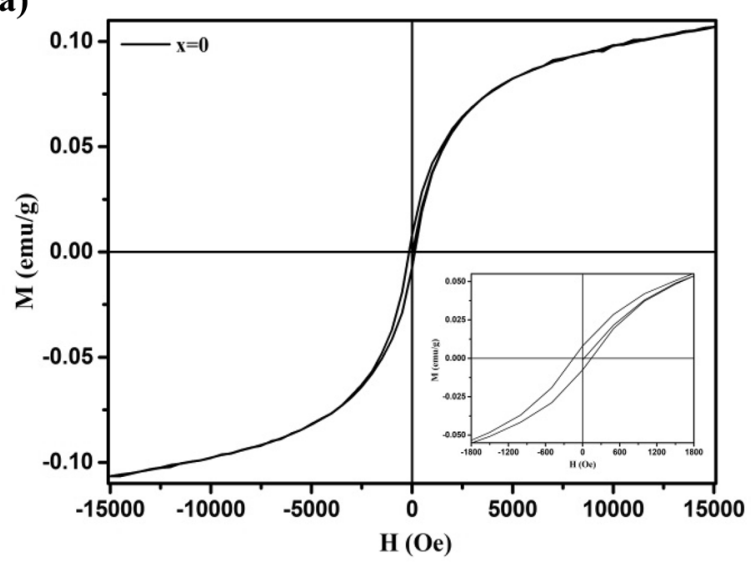

(c)

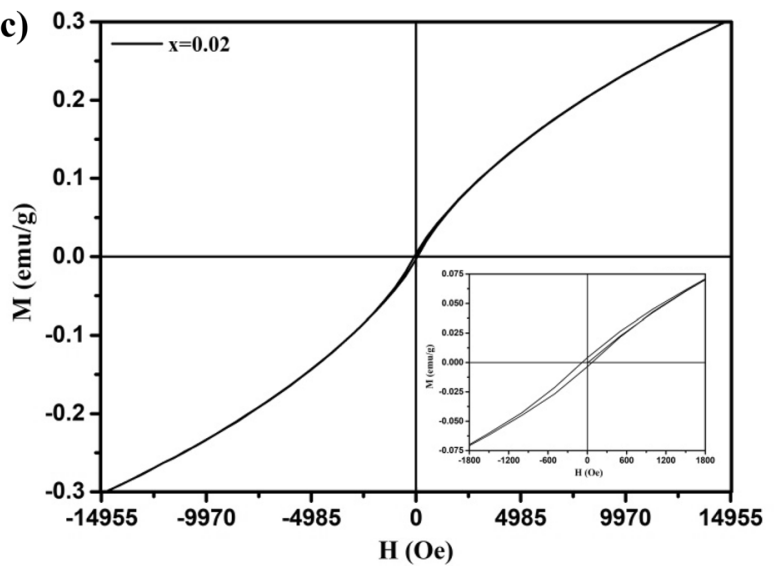

(e)

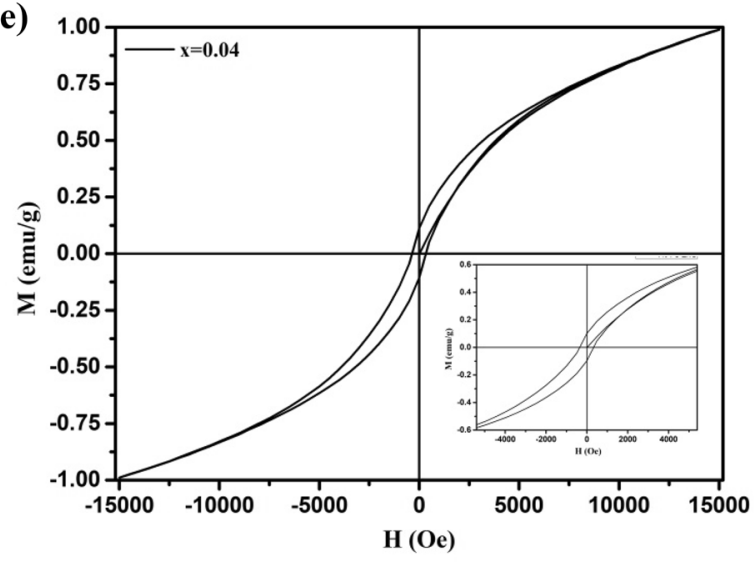

(b)

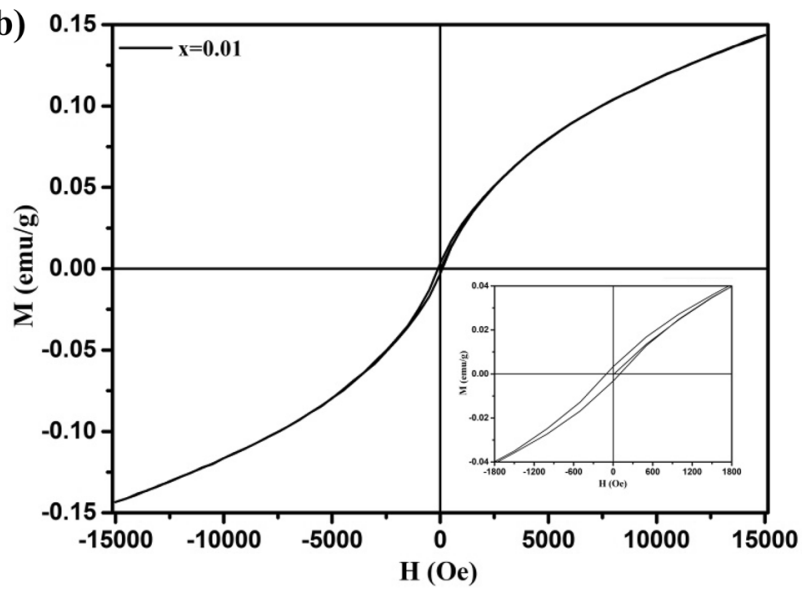

(d)

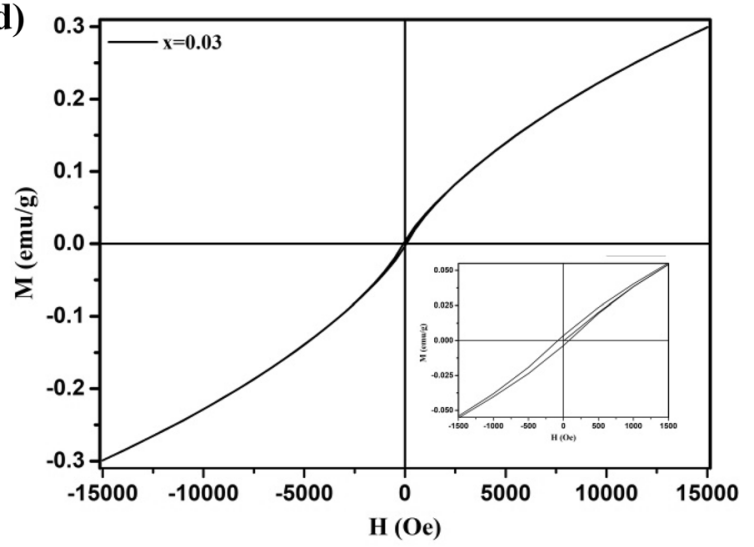

(f)

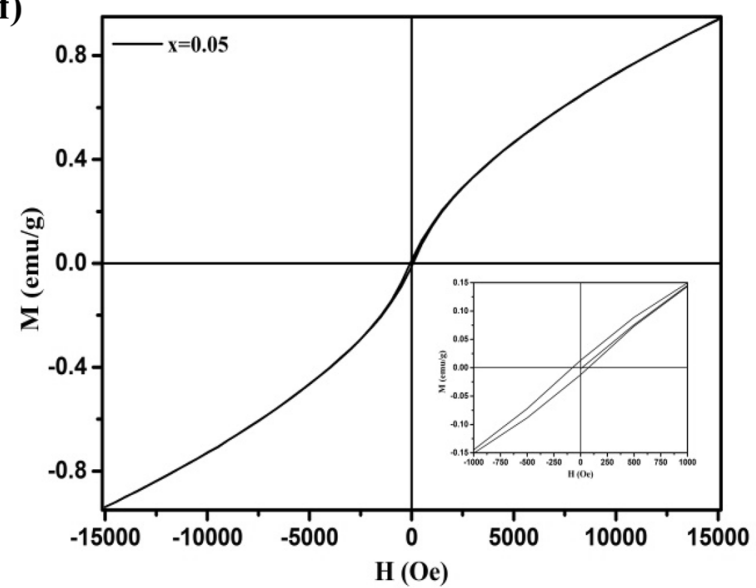

Fig. 8 a-f $M-H$ curve of $Z n_{1-x} \mathrm{Fe}_{x} \mathrm{O}(x=0,0.01,0.02,0.03,0.04,0.05)$, the inset figure shows the enlarged $M-H$ loop

Zener mean-field model (b) carrier-mediated RKKY (Ruderman-Kittel-Kasuya-Yosida) mechanism (c) donor impurity band exchange model, in this, the FM in DMSs is due to an indirect exchange donor electrons and this form a BMPs and (d) direct interactions (such as double or superexchange mechanism). RKKY is not valid as it is based on free electrons and $\mathrm{ZnO}$ is a semiconductor and cannot be converted into metal, double exchange mechanism is also not 
possible because of the very dilute doping of the sample [41]. Hole mediated Zener field model of ferromagnetism may also be excluded since $\mathrm{ZnO}$ is an $n$-type semiconductor [42]. So, the observed ferromagnetism for our sample can be centered on the substitutional behavior of Fe and can be understood based on bound magnetic polarons (BMPs) due to defects. $\mathrm{F}^{+}$is known to be paramagnetic that can activate bound magnetic polaron and these BMPs interact leading to the formation of magnetic domains [43]. As a result, the singly occupied $V_{0}$ may assume to be the cause of ferromagnetism. The interaction between $V_{\text {o }}$ and Fe ions may lead to the formation of BMP in doped samples. The saturation magnetization $\left(M_{S}\right)$ is obtained by drawing a tangential line from the high field loop to the zero-field and is extrapolated. The intercept of the tangent on magnetization axis is taken as the value of $M_{s} . M_{s}$ value increases up to $4 \%$ Fe doped samples and then decreases for $5 \%$ Fe doped $\mathrm{ZnO}$. The enhancement in magnetization may be because of the overlapping of more Fe ions into the ferromagnetic domain with the increase in volume occupied by BMPs in accordance with the explanation given by Hsu et al. for Co-doped $\mathrm{ZnO}$ [44]. The decrease in magnetization may be because of the random distribution of some Fe ions leading to the decrease in net magnetization as mention by lqbal et al. [45]. The result obtained is in accordance with the report given by Agarwal [46] where they observed a decrease in magnetization at higher $\mathrm{Cu}$ concentration. Table 3 shows the value of saturation magnetization $\left(M_{\mathrm{s}}\right)$, coercivity $\left(H_{\mathrm{c}}\right)$, remanence $\left(M_{\mathrm{r}}\right)$.

Models describing the FM and SPM/PM behavior of magnetization curves are not found. The non-saturating hysteresis loop is a phenomenon commonly observed in thin films magnetic oxides. The slope of non-saturation term is known as high field susceptibility. Non-saturation of magnetization is also observed by Margulies [47] in $\mathrm{Fe}_{3} \mathrm{O}_{4}$ films grown by sputter deposition on crystalline substrate and is term as anomalous. The approach to saturation magnetization problem has been discussed in detail by Chakazumi and Charap [48].

Assuming that the presence of restoring force increases with the advance of magnetization towards saturation,

Table 3 summary of $M_{\mathrm{S}^{\prime}} H_{\mathrm{C}^{\prime}} M_{\mathrm{R}^{\prime}} M_{\mathrm{R}} / M_{\mathrm{S}}$ of $\mathrm{Zn}_{1-x} \mathrm{Fe} \mathrm{O}_{x} \mathrm{O}(x=0,0.01,0.02$, $0.03,0.04,0.05)$

\begin{tabular}{llcll}
\hline $\mathrm{Zn}_{1-x} \mathrm{Fe}_{x} \mathrm{O}$ & $M_{\mathrm{s}}(\mathrm{emu} / \mathrm{g})$ & $H_{\mathrm{c}}(\mathrm{Oe})$ & $M_{\mathrm{R}}(\mathrm{emu} / \mathrm{g})$ & $M_{\mathrm{R}} / M_{\mathrm{s}}$ \\
\hline$x=0$ & 0.08056 & 147.63 & 0.0082 & 0.10179 \\
$x=0.01$ & 0.08792 & 106.668 & 0.00326 & 0.03708 \\
$x=0.02$ & 0.11985 & 80.702953 & 0.00385 & 0.03212 \\
$x=0.03$ & 0.12492 & 81.247 & 0.00354 & 0.02834 \\
$x=0.04$ & 0.5655 & 359.0395 & 0.113 & 0.19982 \\
$x=0.05$ & 0.42228 & 79.6043 & 0.01267 & 0.03 \\
\hline
\end{tabular}

SN Applied Sciences the law of approach to saturation magnetization can be expressed as

$M=Q\left(1-\frac{a}{\sqrt{H}}-\frac{b}{H}-\frac{c}{H^{2}}-\cdots\right)+e H$

where $M$ is the actual magnetization value observe at $H$ and the value of constant $Q$ corresponds to its saturation value. $a, b, c$ and $e$ are constants. The term $\frac{a}{\sqrt{H}}$ is credited to the point defects or magnetic anisotropy fluctuation on the atomic scale. The term $\frac{b}{H}$ originated from the local internal stresses caused by dislocation and to voids or nonmagnetic inclusions. $\frac{c}{H^{2}}$ is credited to the weak and large scale fluctuations in the bulk anisotropy. The last term $\mathrm{eH}$ is negligible and hence ignored. It is caused by spontaneous magnetization by the external field. The high field susceptibility fitting curve is shown in Fig. 9. Table 4 shows the value of $Q, a, b$, and $c$.

\section{Conclusion}

In this work structural, optical and magnetic properties of $\mathrm{Zn}_{1-x} \mathrm{Fe}_{x} \mathrm{O}(x=0,0.01,0.02,0.03,0.04,0.05)$ nanoparticles synthesized by hydrothermal method has been studied. XRD results show that the particles exhibited a hexagonal wurtzite structure without any impurity phase and suggest that $\mathrm{Fe}^{2+}$ and $\mathrm{Fe}^{3+}$ ion coexist. Blueshift of optical band gap has been observed for the increase in Fe concentration. PL spectra show the absence of near band edge and all the observed emission peaks are in the visible region. Weak room temperature ferromagnetism even for the pure $\mathrm{ZnO}$ has been observed. The observed hysteresis loop has not been saturated even at high field, may be due to PM and SPM contribution. The observed ferromagnetism is intrinsic and is attributed to BMP. 
(a)

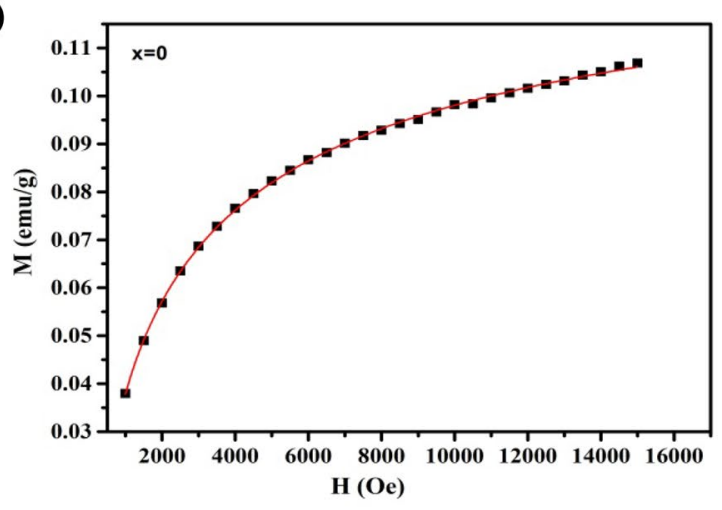

(c)

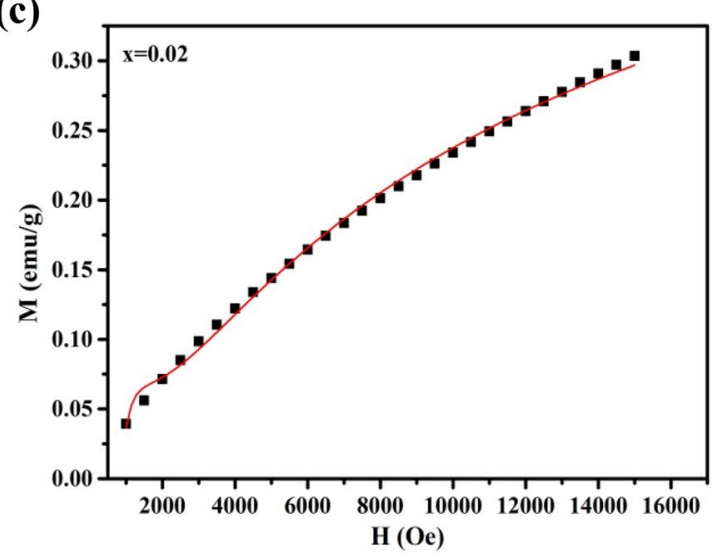

(e)

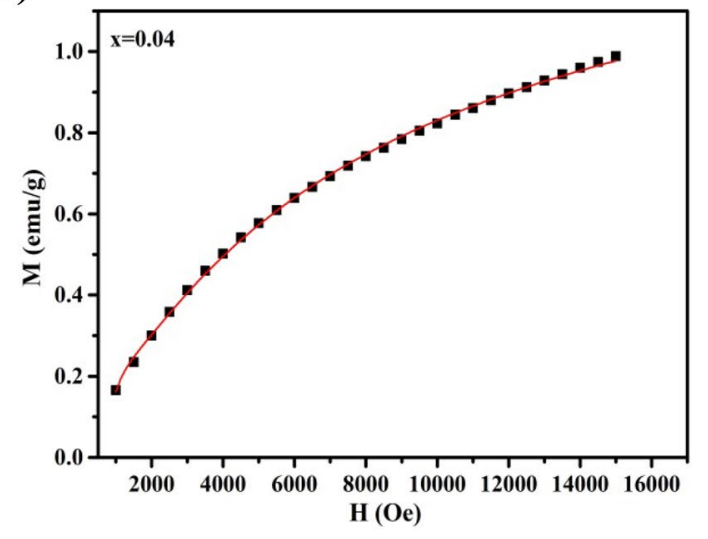

(b)

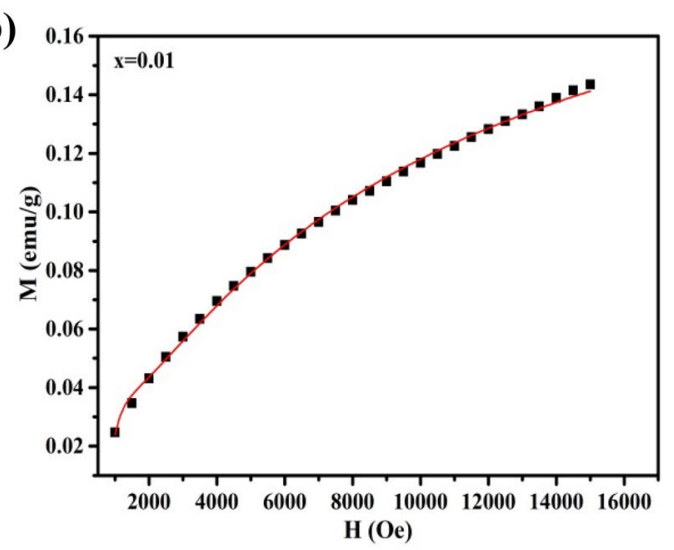

(d)

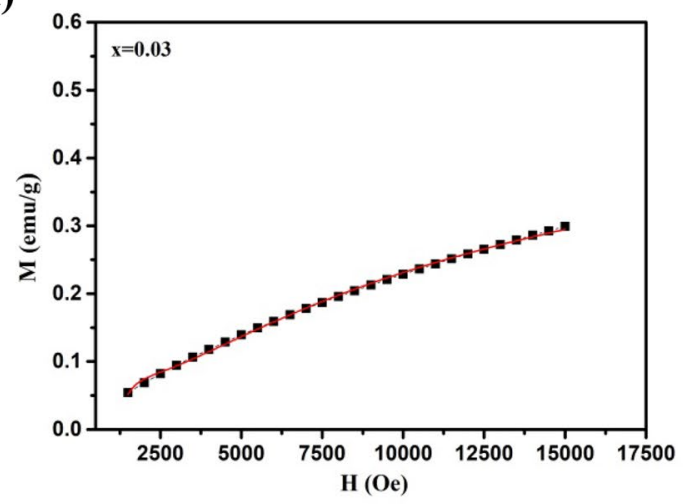

(f)

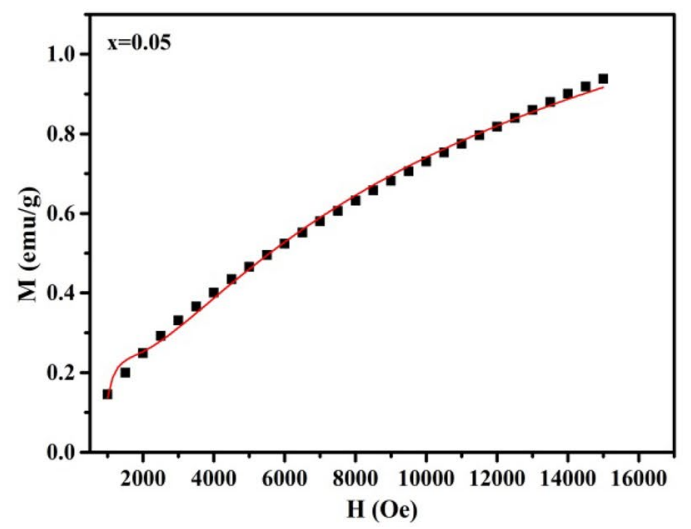

Fig. 9 a-f High field susceptibility fitting of $\mathrm{Zn}_{1-x} \mathrm{Fe}_{x} \mathrm{O}(x=0,0.01,0.02,0.03,0.04,0.05)$ 
Table 4 Values of $Q, a, b, c$

\begin{tabular}{llrrl}
\hline $\mathrm{Zn}_{1-x} \mathrm{Fe}_{x} \mathrm{O}$ & $Q$ & \multicolumn{1}{l}{$a$} & \multicolumn{1}{l}{$b$} \\
\hline$x=0$ & 0.1484 & 39.6404 & -579.4606 & 70,772 \\
$x=0.01$ & 0.2956 & 81.9868 & -2249.0897 & 575,636 \\
$x=0.02$ & 0.7094 & 93.2831 & -2751.9501 & 750,506 \\
$x=0.03$ & 0.7781 & 103.6176 & -3459.7957 & $1.2702 \mathrm{E} 6$ \\
$x=0.04$ & 1.9021 & 74.4994 & -1858.4025 & 417,449 \\
$x=0.05$ & 2.1417 & 91.8403 & -2718.9081 & 751,129 \\
\hline
\end{tabular}

Acknowledgements Authors would like to acknowledge Dr. Naresh Kumar, MNNIT Allahabad, Prayagraj, India for providing the characterization facilities.

\section{Compliance with ethical standards}

Conflict of interest The author(s) declare that they have no competing interests.

\section{References}

1. Chen AJ, Wu XM, Sha ZD, Zhuge LJ, Meng YD (2006) Structure and photoluminescence properties of Fe-doped $\mathrm{ZnO}$ thin films. J Phys D Appl Phys 39(22):4762

2. Liu C, Yun F, Morkoc H (2005) Ferromagnetism of $\mathrm{ZnO}$ and GaN: a review. J Mater Sci Mater Electron 16(9):555

3. Kumar S, Tiwari N, Jha SN, Chatterjee S, Bhattacharyya D, Sahoo NK, Ghosh AK (2015) Insight into the origin of ferromagnetism in Fe-doped $\mathrm{ZnO}$ diluted magnetic semiconductor nanocrystals: an EXFAS study of local structure. RSC Adv 5(115):94658-94669

4. Sinha S, Singh M, Singh RP (2015) ZnO based diluted magnetic semiconductors for spintronic device applications: a review. Int J Emerg Res Manag Technol 4(7):16-20

5. Benramache S, Arif A, Belahssen O, Guettaf A (2013) Study on the correlation between crystallite size and optical gap energy of doped ZnO thin film. J Nanostruct Chem 3(1):80

6. Zhang ZH, Wang X, Xu JB, Muller S, Ronning C, Li Q (2009) Evidence of intrinsic ferromagnetism in individuals dilute magnetic semiconducting nanostructures. Nat Nanotechnol 4(8):523

7. Liu H, Yang J, Zhang Y, Wang Y, Wei M (2008) Ferromagnetism and exchange bias in Fe-doped $\mathrm{ZnO}$ nanocrystals. Mater Chem Phys 112(3):1021-1023

8. Hong NH, Sakai J, Brizé V (2007) Observation of ferromagnetism at room temperature in $\mathrm{ZnO}$ thin films. J Phys Condens Matter 19(3):036219

9. Bhargava R, Sharma PK, Chawla AK, Kumar S, Chandra R, Pandey AC, Kumar N (2011) Variation in structural, optical and magnetic properties of $\mathrm{Zn}_{1-x} \mathrm{Cr}_{x} \mathrm{O}(x=0.0,0.10,0.15$, and 0.20$)$ nanoparticles: role of dopant concentration on non-saturation of magnetization. Mater Chem Physi 125(3):664-671

10. Taher FA, Abdeltwab E (2018) Shape-controlled synthesis of nanostructured $\mathrm{Co}$-doped $\mathrm{ZnO}$ thin films and their magnetic properties. CrystEngComm 20(38):5844-5856

11. Mishra AK, Das D (2010) Investigation on Fe-doped ZnO nanostructures prepared by a chemical route. Mater Sci Eng B 171(1-3):5-10
12. Wei XX, Song C, Geng KW, Zeng F, He B, Pan F (2006) Local Fe structure and ferromagnetism in Fe-doped $\mathrm{ZnO}$ films. J Phys Condens Matter 18(31):7471

13. Xu L, Li X (2010) Influence of Fe-doping on the structural and optical properties of $\mathrm{ZnO}$ thin films prepared by sol-gel method. J Cryst Growth 312(6):851-855

14. Chen ZC, Zhuge LJ, Wu XM, Meng YD (2007) Initial study on the structure and optical properties of $\mathrm{Zn}_{1-x} \mathrm{Fe}_{x} \mathrm{O}$ films. Thin Solid Films 515(13):5462-5465

15. Hammad TM, Griesing S, Wotocek M, Kuhn S, Hempelmann R, Hartmann U, Salem JK (2013) Optical and magnetic properties of Fe-doped $\mathrm{ZnO}$ nanoparticles prepared by the sol-gel method. Int J Nanoparticles 6(4):324

16. Kim KJ, Park YR (2004) Optical investigation of $\mathrm{Zn}_{1-x} \mathrm{Fe}_{x} \mathrm{O}$ films grown on $\mathrm{Al}_{2} \mathrm{O}_{3}$ (0001) by radio-frequency sputtering. J Appl Phys 96(8):4150-4153

17. Abdel-Baset TA, Fang YW, Anis B, Duan CG, Abdel-Hafiez M (2016) Structural and magnetic properties of transition-metaldoped $\mathrm{Zn}_{1-x} \mathrm{Fe}_{x} \mathrm{O}$. Nanoscale Res Lett 11(1):115

18. Salaken SM, Farzana E, Podder J (2013) Effect of Fe-doping on the structural and optical properties of $\mathrm{ZnO}$ thin films prepared by spray pyrolysis. J Semiconduct 34(7):073003

19. Cheng W, Ma X (2009) Structural, optical and magnetic properties of Fe-doped ZnO. J Phys Conf Ser 152(1):012039

20. Kafle BP, Acharya S, Thapa S, Poudel S (2016) Structural and optical properties of Fe-doped ZnO transparent thin films. Ceram Int 42(1):1133-1139

21. Wang C, Chen Z, He Y, Li L, Zhang D (2009) Structure, morphology and properties of Fe-doped $\mathrm{ZnO}$ films prepared by facing-target magnetron sputtering system. Appl Surf Sci 255(15):6881-6887

22. Cullity BD (1956) Elements of X-ray diffraction. Addison-Wesley Publishing, Boston, MA

23. Beltrán JJ, Barrero CA, Punnoose A (2015) Understanding the role of iron in the magnetism of Fe doped $\mathrm{ZnO}$ nanoparticles. Phys Chem Chem Phys 17(23):15284-15296

24. Srivastava A, Kumar N, Khare S (2014) Enhancement in UV emission and bandgap by Fe doping in $\mathrm{ZnO}$ thin films. Opto-Electron Rev 22(1):68-76

25. Pung SY, Lee WP, Aziz A (2012) Kinetic study of organic dye degradation using $\mathrm{ZnO}$ particles with different morphologies as a photocatalyst. Int J Inorg Chem. https://doi. org/10.1155/2012/608183

26. Sharma D, Jha R (2017) Transition metal (Co,Mn) co-doped ZnO nanoparticles: effect on structural and optical properties. J Alloys Compd 698:532-538

27. Parra-Palomino A, Perales-Perez $O$, Singhal $R$, Tomar $M$, Hwang J, Voyles PM (2008) Structural, optical, and magnetic characterization of monodisperse Fe-doped ZnO nanocrystals. J Appl Phys 103(7):07D121

28. Rekha K, Nirmala M, Nair MG, Anukaliani A (2010) Structural, optical, photocatalytic and antibacterial activity of zinc oxide and manganese doped zinc oxide nanoparticles. Phys B 405(15):3180-3185

29. Menon AS, Kalarikkal N, Thomas S (2013) Studies on structural and optical properties of $\mathrm{ZnO}$ and $\mathrm{Mn}$-doped $\mathrm{ZnO}$ nanopowders. Indian J Nanosci 1(1):16-24

30. Singh RPP, Hudiara IS, Rana SB (2016) Effect of calcination temperature on the structural, optical and magnetic properties of pure and Fe-doped ZnO nanoparticles. Mater Sci Poland 34(2):451-459

31. Lu YM, Li XP, Cao PJ, Su SC, Jia F, Han S, Liu WJ, Zhu DL, Ma XC (2012) Study of ultraviolet emission spectra in $\mathrm{ZnO}$ thin films. J Spectrosc. https://doi.org/10.1155/2013/797232 
32. Ischenko V, Polarz S, Grote D, Stavarache V, Fink K, Driess M (2005) Zinc oxide nanoparticles with defects. Adv Funct Mater 15(12):1945-1954

33. Dorranian D, Solati E, Dejam L (2012) Photoluminescence of ZnO nanoparticles generated by laser ablation in deionized water. Appl Phys A 109(2):307-314

34. Kundu S, Sain S, Satpati B, Bhattacharyya SR, Pradhan SK (2015) Structural interpretation, growth mechanism and optical properties of ZnO nanorods synthesized by a simple wet chemical route. RSC Adv 5(29):23101-23113

35. Wu X, Wei Z, Zhang L, Wang X, Yang H, Jiang J (2014) Optical and magnetic properties of Fe doped $\mathrm{ZnO}$ nanoparticles obtained by hydrothermal synthesis. J Nanomater 2014:1-6

36. Ghosh A, Choudhary RNP (2009) Structural evolution and visible photoluminescence of $\mathrm{ZnO}$ nanophosphor. Phys Status Solidi (a) 206(3):535-539

37. Das J, Mishra DK, Srinivasu VV, Sahu DR, Roul BK (2015) Photoluminescence and Raman studies for the confirmation of oxygen vacancies to induce ferromagnetism in Fe doped $\mathrm{Mn}: \mathrm{ZnO}$ compound. J Magn Magn Mater 382:111-116

38. Ovhal MM, Kumar AS, Khullar P, Kumar M, Abhyankar AC (2017) Photoluminescence quenching and enhanced spin relaxation in Fe doped ZnO nanoparticles. Mater Chem Phys 195:58-66

39. Chanda A, Gupta S, Vasundhara M, Joshi SR, Mutta GR, Singh J (2017) Study of structural, optical and magnetic properties of cobalt doped ZnO nanorods. RSC Adv 7(80):50527-50536

40. Sundaresan A, Bhargavi R, Rangarajan N, Siddesh U, Rao CNR (2006) Ferromagnetism as a universal feature of nanoparticles of the otherwise nonmagnetic oxides. Phys Rev B 74(16):161306

41. Rana AK, Kumar $Y$, Rajput $P$, Jha SN, Bhattacharyya D, Shirage PM (2017) Search for the origin of room temperature ferromagnetism properties in $\mathrm{Ni}$-doped $\mathrm{ZnO}$ nanostructure. ACS Appl Mater Interfaces 9(8):7691-7700
42. Ramay SM, Saleem M, Atiq S, Siddiqi SA, Imran M, Al-Zeghayer YS, Al-Awadi AS, Haider S, Mahmood A (2017) RKKY magnetic interactions in chemically synthesized $\mathrm{Zn}_{0.95-x} \mathrm{Fe}_{0.05} \mathrm{Al}_{x} \mathrm{O}(x=0$, $0.03,0.05,0.07)$ nanocrystallites. Arab J Chem 10:S1204-S1208

43. Zhan P, Wang W, Liu C, Hu Y, Li Z, Zhang Z, Zhang P, Wang B, Cao $X$ (2012) Oxygen vacancy-induced ferromagnetism in un-doped ZnO thin films. J Appl Phys 111(3):033501

44. Hsu HS, Huang JCA, Huang YH, Liao YF, Lin MZ, Lee $\mathrm{CH}$, Lee JF, Chen SF, Lai LY, Liu CP (2006) Evidence of oxygen vacancy enhanced room-temperature ferromagnetism in Co-doped $\mathrm{ZnO}$. Appl Phys Lett 88(24):242507

45. Iqbal J, Wang B, Liu X, Yu D, He B, Yu R (2009) Oxygen-vacancyinduced green emission and room-temperature ferromagnetism in Ni-doped ZnO nanorods. New J Phys 11(6):063009

46. Agarwal DC, Singh UB, Gupta S, Singhal R, Kulriya PK, Singh F, Tripathi A, Singh J, Joshi US, Avasthi DK (2019) Enhanced room temperature ferromagnetism and green photoluminescence in Cu doped $\mathrm{ZnO}$ thin film synthesised by neutral beam sputtering. Sci Rep 9(1):1-12

47. Margulies DT, Parker FT, Spada FE, Goldman RS, Li J, Sinclair R, Berkowitz AE (1996) Anomalous moment and anisotropy behavior in $\mathrm{Fe}_{3} \mathrm{O}_{4}$ films. Phys Rev B 53(14):9175

48. Chikazumi S (1955) Physics of magnetism (Wiley, New York, 1964), p. 554. W. Känzig, Phys Rev 9: 98-549

Publisher's Note Springer Nature remains neutral with regard to jurisdictional claims in published maps and institutional affiliations. 